\title{
KEBIJAKAN PENGELOLAAN LINGKUNGAN KAWASAN INDUSTRI SESUAI PROPER KLHK PERINGKAT HIJAU (STUDI KASUS DI KAWASAN INDUSTRI JABABEKA BEKASI)
}

\section{The Policy of Industrial Estate Environmental Management Complying to the Green Rating of "PROPER KLHK" (The Case Study in Jababeka Industrial Estate)}

\author{
Temmy Wikaningrum ${ }^{\mathrm{a}}$, Bambang Pramudya $\mathrm{N}^{\mathrm{b}}$, Erliza Noor ${ }^{\mathrm{c}}$ \\ a Program Studi Pengelolaan Sumber Daya Alam dan Lingkungan, Sekolah Pascasarjana Institut Pertanian Bogor, \\ Kampus IPB Darmaga,Bogor 16680 - twikaningrum@gmail.com \\ ${ }^{b}$ Departemen Teknik Mesin dan Biosistem, Fakultas Teknologi Pertanian, Institut Pertanian Bogor, Kampus IPB \\ Darmaga, Bogor 16680 \\ ${ }^{c}$ Departemen Teknologi Industri Pertanian, Fakultas Teknologi Pertanian, Institut Pertanian Bogor, Kampus IPB \\ Darmaga, Bogor 16680
}

\begin{abstract}
Environmental management in industrial estate is the strategic policy model which is needed to be developed referring to the Indonesian Government Decree number 24 year 2009, that state almost all of the new industrial developments should be located in industrial estate. The complexity in this environmental management was approached by "green rating" of PROPER's criteria regulated by Ministry of Environment \& Forestry (KLHK). PROPER is the assessment program of company performance rating in environmental management. Green rating is classified by PROPER in terms of beyond compliance performance. The result of the case study in Jababeka Industrial Estate (KIJA) Bekasi, based on its environmental situational analysis year 2014 by multidimensional scaling (MDS) method, showed that only the management dimension had a sustainability performance. The results of prospective analysis on leverage factors of MDS showed that the key factors of the environmental management model were (1) DRKPL (summary document of environmental management performance), (2) implementation of water conservation and reducing water pollution program, (3)funding for water conservation, (4) monitoring and evaluation of community development program, (5) implementation of $3 R$ (reduce, reuse, recycle) programs of hazardous waste, (6) technology of $3 R$, and (7) benchmarking. Based on the key parameters and referred to the possibilities conditions, three scenarios have been developed to approach the implementative policy. The moderate scenario was recommended to be the right policy in term of consideration of technology, funding availability, time of implementation and organization skills.
\end{abstract}

Keywords: environmental management, industrial estate, jababeka, proper KLHK

(Diterima: 27-05-2015; Disetujui: 09-07-2015)

\section{Pendahuluan}

Sejalan dengan tujuan pembangunan berkelanjutan, pertumbuhan ekonomi harus diiringi dengan peningkatan pengelolaan lingkungan serta sektor-sektor penting yang berperan dalam pertumbuhan ekonomi tersebut. Salah satu sektor yang penting adalah sektor industri. Sektor industri memberikan kontribusi sebesar $1.42 \%$ dari pertumbuhan ekonomi nasional sebesar $5.78 \%$ pada tahun 2013 terhadap 2012 tanpa migas, sedangkan bila dengan migas $6.28 \%$ (sumber www.bps.go.id).

Dengan demikian kajian mengenai keberhasilan pengelolaan lingkungan hidup di Indonesia tidak dapat terlepas dari kajian atas pertumbuhan kegiatan industrinya. Dengan pesatnya pertumbuhan sektor industri di Indonesia, telah diterbitkan Peraturan Pemerintah No 24 tahun 2009 yang antara lain mengatur keharusan perusahaan industri yang baru didirikan agar berlokasi di kawasan industri. Hal ini berarti adanya kebutuhan penyediaan lahan kawasan industri agar dapat mengimbangi permintaan pasar. Dengan demikian kebutuhan suatu sistem yang tepat dalam kebijakan pengelolaan lingkungan kawasan industri sangat dibutuhkan.

Berkaitan dengan pengelolaan kawasan industri, menurut penelitian tentang ekologi industri di Russia oleh Salmi dan Toppinen (2007), disimpulkan bahwa kerangka umum instrumen kebijakan efisiensi, ekonomi, dan lingkungan harus selaras dengan persepsi lokal. Penelitian Salim et al. (2009) mengenai model strategi pengelolaan limbah baja di wilayah pesisir kawasan industri Krakatau Cilegon menyimpulkan bahwa strategi pengelolaan lingkungan dapat dilakukan secara bersamaan antara aktivitas penduduk dan aktivitas industri, dengan prioritas variabel strategi berupa pencegahan timbulnya limbah pada pengelolaan limbah baja.

Menurut Ghasemian (2012) yang meneliti kawasan industri di Isfahan Iran menyatakan bahwa kualitas lingkungan kawasan perumahan dengan radius $2500 \mathrm{~m}$ diperkirakan terkena dampak kawasan industri, sehingga seharusnya AMDAL agar dibuat dengan lebih antisipatif.

Pengelolaan lingkungan kawasan industri merupakan permasalahan yang relatif kompleks. Hal ini karena 
melibatkan berbagai pemangku kepentingan yang saling berinteraksi. Dengan demikian pendekatan yang bersifat komprehesif diperlukan agar lebih mewakili (representative) terhadap kenyataan permasalahan yang sebenarnya (Kodrat 2006). Untuk itu diperlukan analisis atas kondisi pengelolaan yang sedang berlangsung. Mengingat kemajemukan tolok ukur pengelolaan lingkungan bagi suatu kawasan industri, dalam penelitian ini kriteria pengelolaan lingkungan dilakukan dengan analisis berdasarkan kriteria penilaian PROPER (Penilaian Peringkat Kinerja Perusahaan dalam Pengelolaan Lingkungan) peringkat hijau. Ketentuan PROPER pada penelitian ini mengacu pada Peraturan Menteri Lingkungan Hidup No: 03 tahun 2014 mengenai Program Penilaian Peringkat Kinerja Perusahaan dalam Pengelolaan Lingkungan Hidup.

Berdasarkan perbedaan keadaan yang diinginkan sesuai kriteria peringkat hijau PROPER dengan kondisi situasional yang sebenarnya, selanjutnya dibuat model kebijakan. Diharapkan model tersebut menjadi pertimbangan untuk pembuatan koreksi atas kebijakan dalam pengelolaan lingkungan hidup agar sesuai dengan kriteria yang diinginkan. Peringkat hijau dalam PROPER merupakan kategori melampaui standar ketaatan (beyond compliance) atas peraturan dan perundang-undangan yang berlaku.

Perkembangan PROPER tidak dapat terlepas dari program Prokasih sejak tahun 1990 hingga tahun 1995. PROPER merupakani perbaikan dan penyempurnaannya dari Prokasih sejak tahun 2002. Penilaian PROPER berdasarkan kriteria yang berbeda-beda, yang makin lama makin disempurnakan, ketat, dan rinci. Pelaksanaan PROPER dilakukan terhadap usaha dan /atau kegiatan wajib Amdal atau UKL-UPL (Upaya Pengelolaan dan Pemantauan Lingkungan), yang a) hasil produknya tujuan ekspor, b) terdapat dalam pasar bursa, c) menjadi perhatian masyarakat dalam lingkup regional maupun nasional, d) skala kegiatan signifikan untuk menimbulkan dampak terhadap lingkungan hidup (KLH 2012).

Pelaporan ketaatan lingkungan wajib disusun sebagai Dokumen Ringkasan Kinerja Pengelolaan Lingkungan (DRKL) dengan mengikuti format tertentu mengikuti ketentuan pada Lampiran II Peraturan Menteri LH No 3 tahun 2014. Selanjutnya status ketaatan akan menjadi dasar pemeringkatan dari yang terendah hitam, merah, biru, hijau, dan yang tertinggi peringkat emas. Adapun peringkat biru untuk penanggung jawab usaha dan/ atau kegiatan yang telah sesuai dengan persyaratan sebagaimana diatur dalam peraturan perundang-undangan.

Menurut KLH (2012), untuk penanggung jawab usaha dan/atau kegiatan yang memperoleh peringkat biru dengan syarat a) tidak ada temuan yang signifikan pada saat dilakukan pengawasan dan b) tidak terjadi konflik dengan masyarakat pada saat dan setelah dilakukan pengawasan, dapat dilakukan penilaian melebihi ketaatan dengan menyerahkan DRKPL yang meliputi a) penerapan sistem manajemen lingkungan, b) pencapaian di bidang efisiensi energi, c) pengurangan dan pemanfaatan limbah bahan berbahaya dan beracun (B3), d) penerapan prinsip pengurangan, penggunaan kembali dan daur ulang limbah padat non $\mathrm{B} 3, \mathrm{e})$ pengurangan pencemar udara dan emisi gas rumah kaca, f) pencapaian di bidang efisiensi air dan penurunan beban pencemaran air, g) perlindungan keanekaragaman hayati, dan h) pemberdayaan masyarakat.

Selanjutnya dari hasil evaluasi dan penilaian melebihi ketaatan, dihasilkan peringkat hijau untuk penanggung jawab usaha dan/ atau kegiatan yang telah melakukan pengelolaan lingkungan hidup dalam bidang sistem manajemen lingkungan, pemanfaatan sumber daya secara efisien dan melakukan upaya pemberdayaan masyarakat dengan baik.

Penelitian ini dilakukan dengan tujuan utama membuat skenrio kebijakan pengelolaan lingkungan kawasan industri sesuai dengan kriteria PROPER KLHK peringkat hijau. Untuk mencapai tujuan itu dilakukan beberapa tahapan tujuan khusus yaitu:

a. Menganalisis perkembangan kinerja keberlanjutan pengelolaan lingkungan selama tahun 2008 sampai tahun 2014 ditinjau dari dimensi ekonomi, teknologi, ekologi, sosial, dan kelembagaan dengan menggunakan atribut sesuai multi dimensi kriteria PROPER KLHK peringkat hijau.

b. Menentukan faktor-faktor pengungkit pengelolaan lingkungan kawasan industri berdasarkan analisis multi dimensi kondisi tahun 2014 sebagai base line.

c. Mengindentifikasi faktor-faktor penting yang berpengaruh dalam pengelolaan lingkungan kawasan industri dengan analisis prospektif.

d. Menyusun skenario kebijakan operasional yang implementatif pada pengelolaan lingkungan kawasan industri dengan kriteria PROPER KLHK peringkat hijau berdasarkan faktor-faktor penting dan berpengaruh pada keadaan yang mungkin terjadi di masa mendatang.

\section{Metodologi}

\subsection{Tempat, Waktu Penelitian dan Pengumpulan Data}

Penelitian dilakukan di kawasan industri Jababeka (KIJA) yang berlokasi di Cikarang Kabupaten Bekasi. Dengan akses jalan tol Jakarta-Cikampek km 31 dan 24.7, KIJA mengalami pertumbuhan yang pesat. KIJA mempunyai luas sebesar 510 ha pada saat berdiri tahun 1989 dan awal tahun 2015 telah mencapai lebih dari 3.000 ha. Total proyek KIJA seluas 5.600 ha termasuk kawasan perumahan, lapangan golf, kawasan komersial, kawasan pendidikan, pelabuhan darat, serta pembangkit listrik. Pemilihan lokasi penelitian berdasarkan pertimbangan skala luas kawasan yang besar, telah beroperasi lebih dari 25 tahun, tempat berlokasinya lebih dari 1.650 perusahaan industri dan komersial yang berasal dari 30 negara, serta jenis industri yang beragam. Jenis industri di KIJA terdiri dari industri tekstil, makanan dan minuman, kimia, farmasi, elektronik, otomotif, kosmetik dan aneka industri lainnya. 
Menurut Dewi (2009), output perekonomian Kabupaten Bekasi sangat dipengaruhi secara signifikan oleh ouput sektor industrinya, sedangkan output sektot industrinya dipengaruhi oleh investasi asing dan nilai ekspor.

Penelitian dilakukan selama 4 bulan, yaitu dari bulan Januari 2015 sampai dengan April 2015. Data yang dikumpulkan meliputi data sekunder maupun data primer.

\subsection{Alat dan Bahan}

Komputer dilengkapi dengan software Rapfish dan software Excel.

\subsection{Prosedur Penelitian}

a. Dilakukan pengamatan kondisi di lokasi penelitian dan pengambilan data sekunder pada Manajemen KIJA. Selain itu data sekunder pendukung juga berasal Pemerintah Daerah Kabupaten Bekasi, Badan Pengelolaan Lingkungan Hidup Daerah (BPLHD) Jawa Barat, dan Kementerian Lingkungan Hidup dan Kehutanan. Selain itu, beberapa data diambil juga dari publikasi resmi dari instansi-instansi terkait.

b. Dilakukan interview terhadap para pakar yang terpilih. Dalam penelitian ini terdiri dari tiga kelompok sesuai dengan tahapan penelitian:

- Tahapan penentuan atribut, definisi, serta kriteria skor dalam analisis MDS berdasarkan kriteria PROPER KLHK peringkat hijau sesuai Peraturan Menteri Lingkungan Hidup No 03 tahun 2014. Dalam tahap ini dilaksanakan dengan tiga orang pakar, yaitu dari pihak perusahaan KIJA, perusahaan industri dan Kementerian KLHK.

- Tahapan pengisian skor atribut MDS dengan cara FGD (forum group discussion) internal KIJA. FGD bersifat internal karena data-data yang digunakan berasal dari data tahunan PROPER perusahaan tahun 2008 sampai dengan 2014.

- Tahapan analisis prospektif dengan pengisian form kuesioner oleh enam orang pakar yang terdiri dari manajemen KIJA, tokoh masyarakat, perusahaan industri, Dinas Lingkungan Hidup Bekasi, BPLHD Jawa Barat, dan Kementerian KLHK.

c. Membangun skenario kebijakan yang implementatif berdasarkan faktor-faktor kunci hasil dari analisis prospektif.

\subsection{Analisis Data}

Analisis data dilakukan dengan beberapa tahapan yang terdiri dari: a. Analisis situasional, yaitu membuat kajian kondisi berdasarkan data tahunan kinerja pengelolaan KIJA dari tahun 2008 sampai dengan tahun 2014. Analisis juga juga didukung data-data sekunder lain dari instansi-instansi yang terkait.

b. Analisis multi dimensi (MDS) dilakukan dengan bantuan software rapfish yang telah dimodifikasi menjadi rap-Proindes, yaitu rapid analysis of Proper's industrial estate. Dari hasil analisis MDS diperoleh faktor-faktor penting dalam pengelolaan lingkungan kawasan industri. Menurut Kavanagh dan Pitcher (2004), metoda rapfish memiliki beberapa keunggulan yaitu sederhana, mudah, cepat, serta biaya yang murah. Hasil analisis MDS tahun 2014 sebagai base line untuk analisis prospektif lebih lanjut.

c. Analisis prospektif atas hasil analisis MDS oleh Dewan Pakar yang dipilih secara purposive sesuai bidang keahlian dan kepakarannya. Hasil analisis propektif adalah faktor-faktor penentu dan penghubung yang selanjutnya digunakan untuk membangun model.

\section{Hasil dan Pembahasan}

\subsection{Analisis Situasional}

Data kondisi pengelolaan lingkungan KIJA dari tahun 2008 sampai dengan tahun 2014 menunjukkan telah dilakukan upaya-upaya sehingga sesuai dengan persyaratan sebagaimana diatur dalam peraturan perundang-undangan. Ini dibuktikan dengan selalu tercapainya PROPER peringkat biru, bahkan pada tahun 2009 dan 2011 dicapai peringkat hijau. Ini menunjukkan pada tahun 2009 dan 2011 pernah berhasil mencapai kriteria beyond compliance. Ringkasan implementasinya terhadap 8 kriteria PROPER peringkat hijau adalah sebagai berikut:

a. Sistem Manajemen Lingkungan : telah diimplementasikan integrasi QHSE yaitu quality, health, safety and environment, dengan implementasi ISO 9001: 2008, OHSAS 18001: 2007, ISO 14001: 2004, serta akreditasi ISO 17025 untuk laboratorium lingkungan.

b. Pengelolaaan sumberdaya:

- Energi: dilakukan upaya efisiensi dengan pemasangan alat inverter dengan perubahan sistem filtrasi dari sistem pompa menjadi gravitasi pada instalasi air bersih maupun air limbah.

- Air: dilakukan upaya penurunan air yang "hilang" pada sistem distribusi air bersih.

- Emisi udara: penanaman pohon, dan penggantian material non CFC pada APAR dan sistem air conditioning.

- Limbah padat B3: penurunan volume limbah B3 dengan perbaikan sistem pengeringan dan kerjasama dengan industri semen sebagai alternatif material.

- Limbah padat non B3: pengoperasioan pilot project pada unit composting. 
- Keanekaagaman hayati: pembangunan botanical garden, pengembangan tanaman langka, dan organic farming.

c. Pengembangan masyarakat: dilakukan pemetaaan sosial serta dilakukan program pemberdayaan ekonomi, sosial, pendidikan, serta bantuan kesehatan.

\subsection{Analisis Multi Dimensi}

Analisis Multi Dimensional Scaling (MDS) yang dilakukan dalam penelitian ini terdiri dari dimensi ekologi, ekonomi, sosial, teknologi serta kelembagaan yang disusun berdasarkan kriteria peringkat hijau PROPER sesuai Peraturan Menteri Lingkungan Hidup No 03 tahun 2014. Kelima dimensi utama dalam pengelolaan lingkungan tersebut sejalan bila dibandingkan dengan hasil penelitian Jampanil et al. (2012), yang mengevaluasi tentang penerapan ekologi industri di kawasan industri Maptaphut Thailand dengan hasil terdapat 5 (lima) faktor penting yaitu fisik, ekonomi, sosial, lingkungan dan manajemen.

Visualisasi posisi titik keberlanjutan dalam analisis MDS disajikan dalam sumbu vertikal dan horizontal yang pada akhirnya berupa bentuk diagram layanglayang (kite diagram).

Pada penelitian ini, kinerja lima dimensi pengelolaan lingkungan kawasan industri dari tahun 2008 sampai dengan tahun 2014 secara umum menunjukkan peningkatan, meskipun secara masing-masing dimensi mengalami kinerja fluktuasi naik turun. Untuk analisis tahun 2014, dapat dilihat pada Gambar 1 sampai dengan Gambar 10, termasuk atribut yang menjadi pengungkit atau faktor penting yang akan digunakan pada kajian lebih lanjut dalam analisis prospektif.

Menurut Kavanagh dan Pitcher (2004), nilai skor pada diagram layang adalah 0 untuk buruk dan 100 untuk baik. Menurut Fauzy dan Anna (2005), nilai indeks termasuk kategori tidak keberlanjutan / buruk $(<25.00)$, kurang berkelanjutan (25.001-50.00), cukup berkelanjutan (50.01-75.00), dan sangat berkelanjutan/baik (75.01-100.00)

Untuk dimensi ekologi sesuai Gambar 1, nilai keberlnjutan sebesar 40.87 (kurang berkelanjutan). Sessuai Gambar 2, tiga faktor penting berdasarkan nilai RMS (root mean square) yang melebihi median yang menjadi faktor pengungkit adalah (1) program implementasi 3R (reduce, reuse, recycle) limbah B3 (bahan berbahaya dan beracun), (2) penurunan pencemaran udara, serta (3) konservasi air dan penurunan beban pencemaran air limbah.

Dari dimensi ekonomi sesuai Gambar 3, nilai keberlanjutan ekonomi sebesar 35.06 (kurang keberlanjutan). Sesuai Gambar 4, terdapat lima faktor pengungkit dengan nilai RMS > median, yaitu adalah alokasi dana untuk (1) pengembangan masyarakat , (2) penurunan emisi udara, (3) konservasi air dan penurunan beban pencemaran air, (4) program 3R limbah B3, dan (5) implementasi sistem manajemen lingkungan (SML).

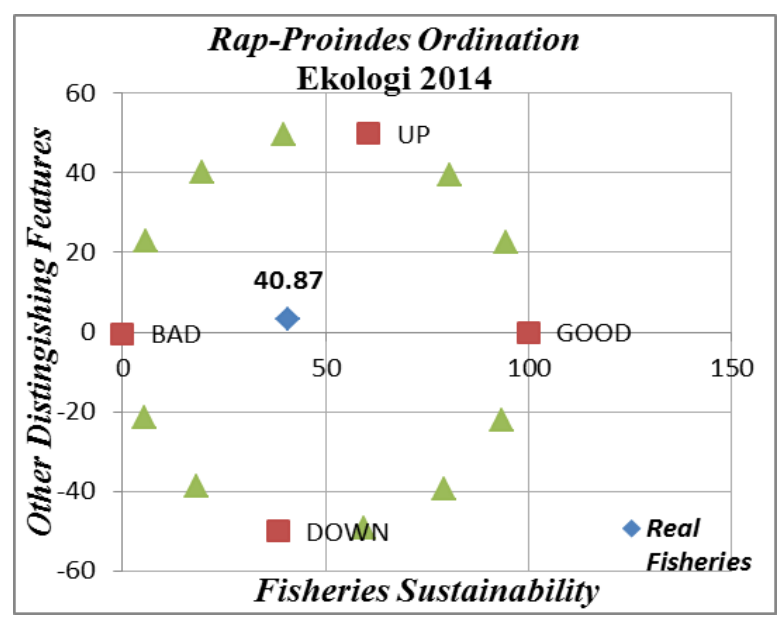

Gambar 1. Nilai keberlanjutan dimensi ekologi

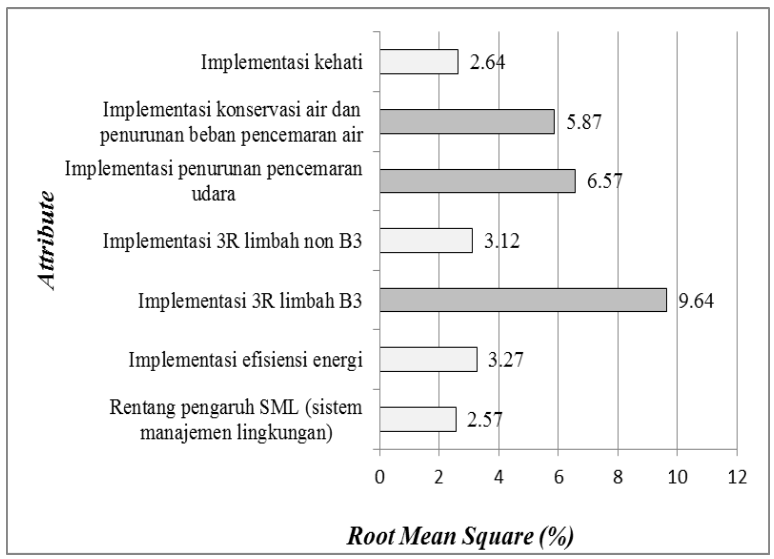

Gambar 2. Faktor-faktor penting dimensi ekologi

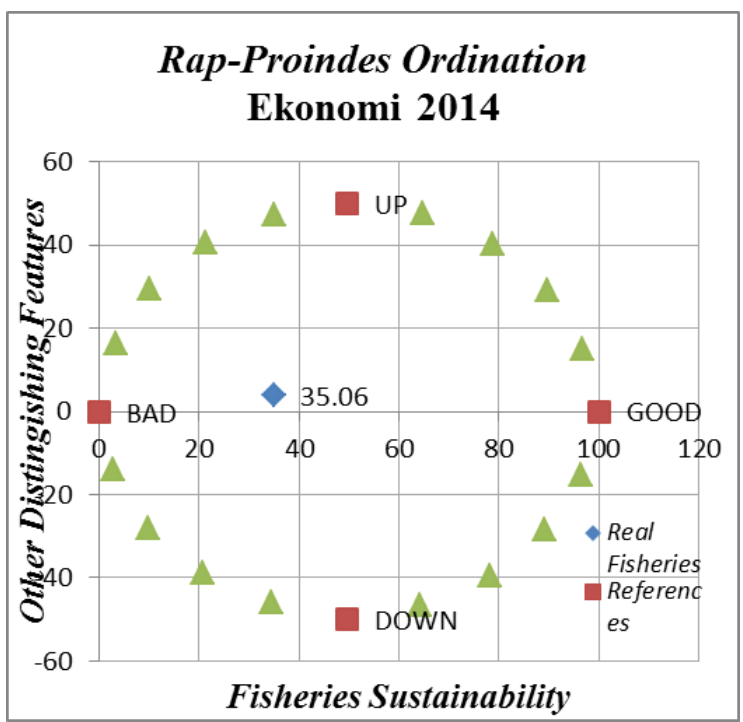

Gambar 3. Nilai keberlanjutan dimensi ekonomi

Menurut Gambar 5, hasil nilai keberlanjutan MDS dimensi sosial sebesar 28.58 yang berarti kurang berkelanjutan. Dua faktor penting sebagai pengungkit dengan nilai RMS > median adalah (1) hubungan sosial internal dan eksternal, dan (2) monitoring dan evaluasi program pengembangan masyarakat (Gambar 6). 


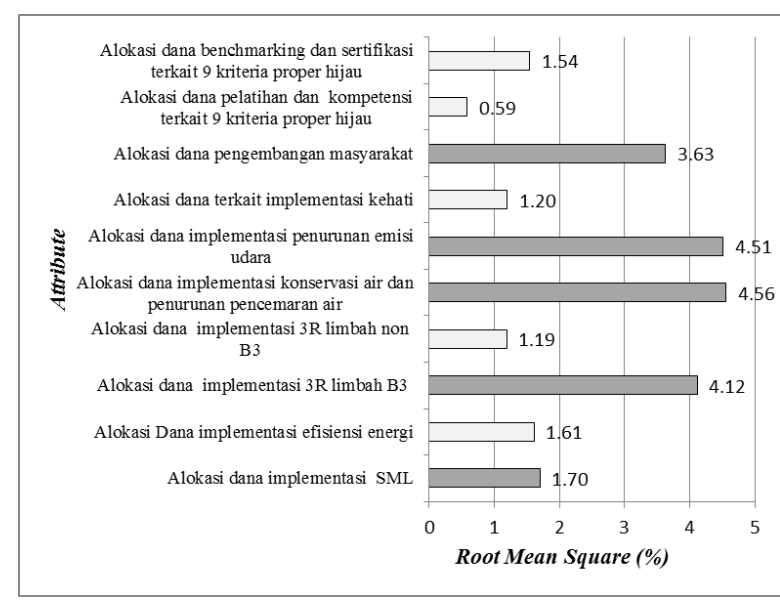

Gambar 4. Faktor-faktor penting dimensi ekonomi

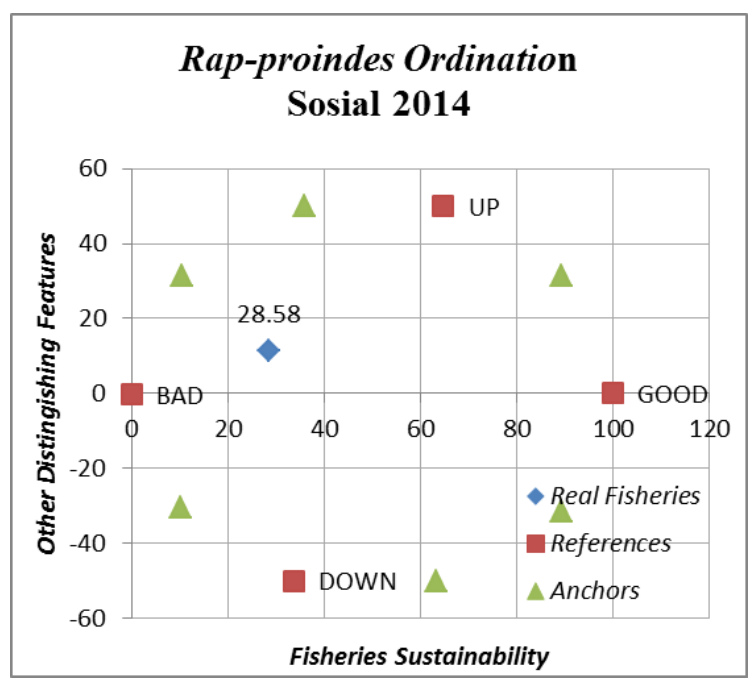

Gambar 5. Nilai keberlanjutan dimensi sosial

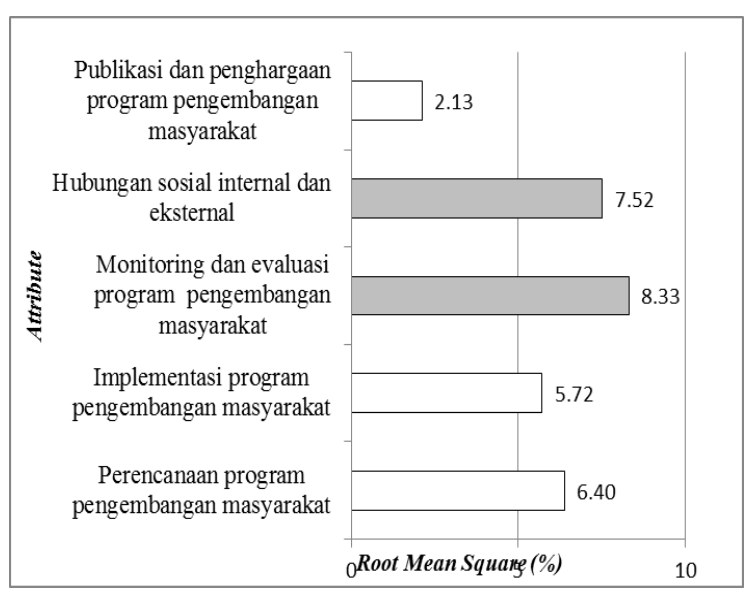

Gambar 6. Faktor-faktor penting dimensi sosial

Gambar 7 yang menunjukkan nilai status keberlanjutan teknologi sebasar 16.53 yang berarti tidak berkelanjutan. Tiga faktor penting yang menjadi pengungkit dengan nilai RMS > median adalah adalah (1) teknologi penurunan pencemaran udara, (2) teknologi 3R limbah B3, dan (3) teknologi audit energi (Gambar 8).

Dari dimensi kelembagaan yang ditunjukkan pada Gambar 9, nilai keberlanjutan sebesar 66.91 (cukup berkelanjutan). Tiga faktor penting berdasarkan nilai
RMS nya > median adalah (1) benchmarking baik secara nasional maupun internasional, dan (2) DRKPL (Dokumen Ringkasan Kinerja Pengelolaan Lingkungan).

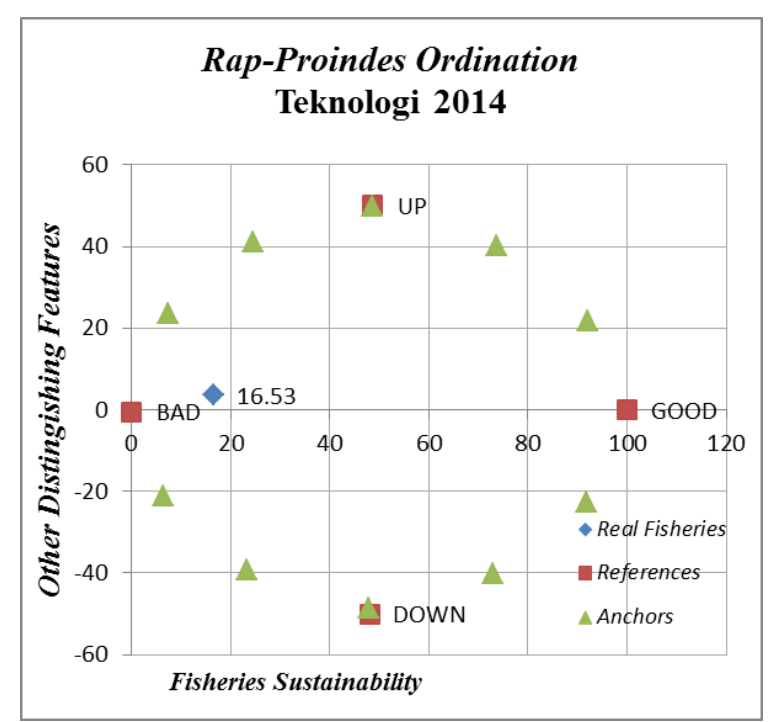

Gambar 7. Nilai keberlanjutan dimensi teknologi

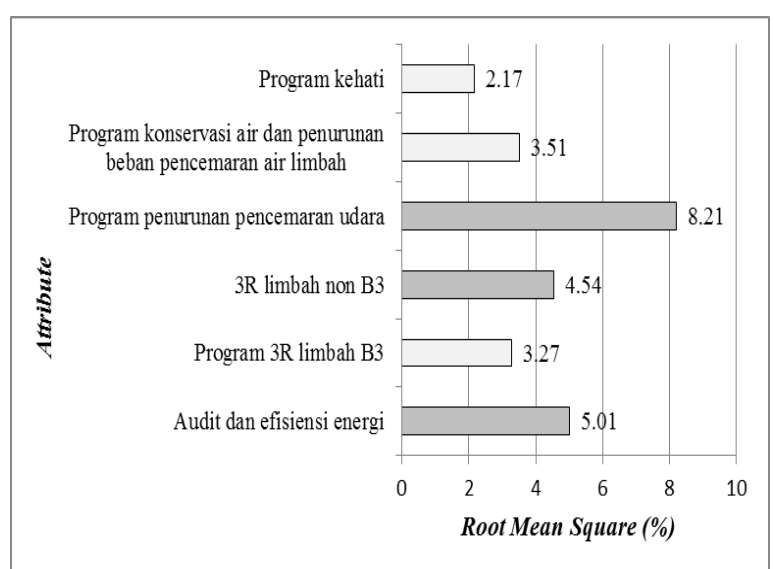

Gambar 8. Faktor-faktor penting dimensi teknologi

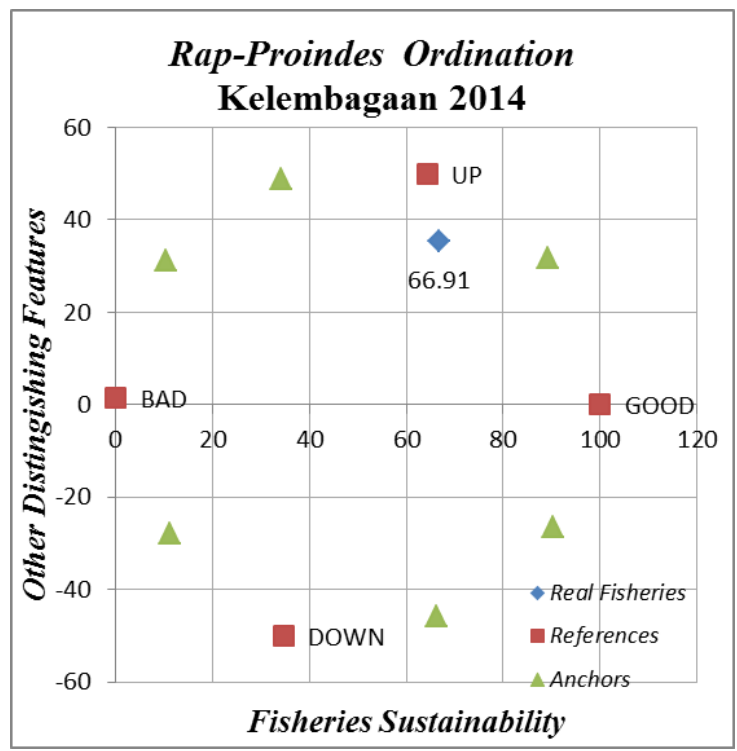

Gambar 9. Nilai keberlanjutan dimensi kelembagaan 


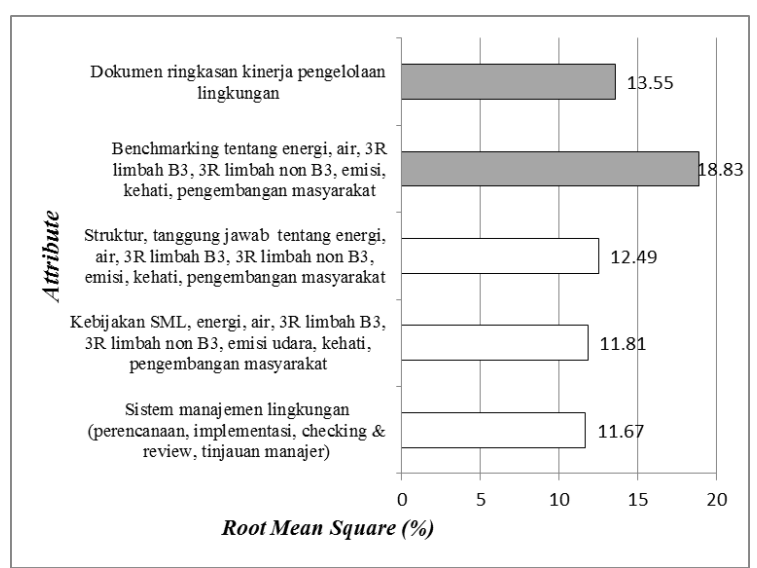

Gambar 10. Faktor-faktor penting dimensi kelembagaan

Berdasarkan nilai keberlanjutan lima dimensi hasil analisis MDS sesuai data tahun 2014, dapat disusun diagram layang sesuai Gambar 11.

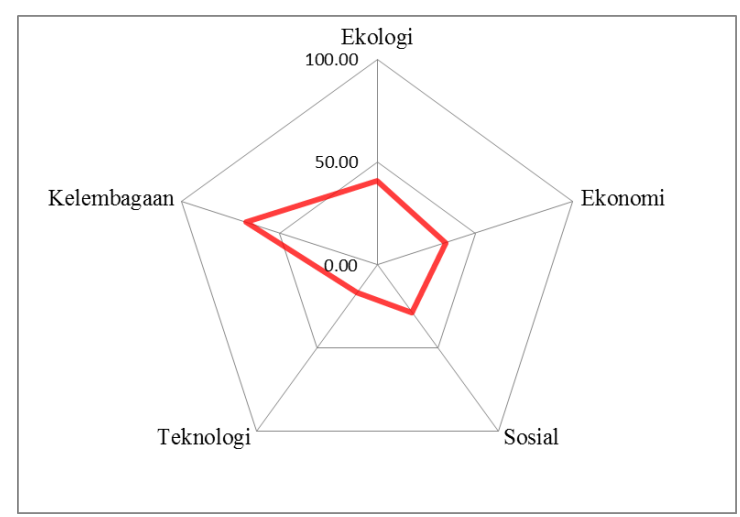

Gambar 11. Status keberlanjutan hasil MDS 2014

Berdasarkan skor yang diberikan Suyitman (2010), dari hasil penelitian ini menunjukkan bahwa hanya dimensi kelembagaan yang mempunyai status keberlanjutan karena mempunyai skor > 50 dari tahun 2008 sampai dengan 2014. Sedangkan dimensi lainnya yaitu ekologi, ekonomi, sosial dan teknologi belum masuk dalam kategori keberlanjutan.

Faktor-faktor penting sebanyak 15 yang menjadi pengungkit sistem dari hasil analisis MDS tahun 2014 tersebut di atas diringkas pada Tabel 1.

\subsection{Hasil Analisis Prospektif}

Dalam analisis prospektif, dilakukan in-depth interview terhadap 6 orang pakar yang mewakili dari berbagai pemangku kepentingan.

Menurut Byl et al. (2001), pemetaan nilai skor hasil analisis prospektif disajikan dalam bagan tingkat pengaruh terhadap ketergantungan dengan skor 0 sampai dengan 3 berdasarkan tingkatnya. Dalam penelitian ini bagan tersebut dapat dilihat dalam Gambar 12 .

Dari pemetaan faktor pengungkit pengelolaan lingkungan kawasan industri tersebut diperoleh hasil tujuah faktor-faktor kunci yang penting yang terletak pada kuadran I dan II, yaitu (1) DRKPL, (2) benchmarking tentang energi, air, 3R limbah B3, 3R limbah non B3, emisi, kehati, pengembangan masyarakat, (3) implementasi konservasi air dan penurunan beban pencemaran air, (4) implementasi program 3R limbah B3, (5) monitoring dan evaluasi program pengembangan masyarakat, (6) alokasi dana implementasi konservasi air dan penurunan beban pencemaran air, (7) teknologi program 3R limbah B3.

Tabel 1. Faktor-faktor penting hasil analisis MDS

\begin{tabular}{lll}
\hline Dimensi & Faktor pengungkit \\
\hline \multirow{2}{*}{ Ekologi } & 1 & Implementasi 3R limbah B3 \\
& 2 & Implementasi penurunan pencemaran udara \\
& 3 & Implementasi konservasi air dan penurunan beban pencemaran air \\
& 4 & Alokasi dana konservasi air dan penurunan beban pencemaran air \\
& 5 & Alokasi dana penurunan pencemaran udara \\
Ekonomi & 6 & Alokasi dana 3R limbah B3 \\
& 7 & Alokasi dana pengembangan masyarakat \\
& 8 & Alokasi dana implementasi sistem manajemen lingkungan \\
& 9 & Monitoring dan evaluasi program pengembangan masyarakat \\
Sosial & 10 & Hubungan sosial (internal dan eksternal) \\
& 11 & Teknologi penurunan pencemaran udara \\
& 12 & Teknologi efisiensi energi \\
& 13 & Teknologi 3R limbah B3 \\
& 14 & Benchmarking (secara regional, nasional, internasional) \\
& 15 & Dokumen Ringkasan Kinerja Pengelolaan Lingkungan (DRKPL) \\
\hline
\end{tabular}

Tujuh faktor-faktor yang kunci yang berpengaruh tersebut apabila dibandingkan dengan status keberlanjutan tahun 2014 sebagai base line dapat dilihat pada Tabel 2. Pada Tabel 2 tersebut dapat dilihat bahwa pada setiap dimensi terdapat faktor yang sangat berpengaruh bagi sistem pengelolaan lingkungan kawasan industri sesuai kriteria PROPER KLHK peringkat hijau mengingat status pada dimensi ekologi, ekonomi, sosial dan teknologi belum ada yang berkelanjutan. Sedangkan pada dimensi kelembagaan yang sudah termasuk cukup berkelanjutan terdapat faktor penting DRKPL selain benchmarking.

Hasil analisis prospektif ini dibandingkan dengan hasil penelitian Napitupulu (2009) mengenai Model Kebijakan Pengelolaan berkelanjutan pada PT Kawasan Berikat Nusantara Jakarta yang menghasilkan empat faktor kunci yang yaitu a) teknologi limbah cair, b) partisipasi pengusaha dalam pengelolaan lingkungan, c) ketersediaan sarana dan prasarana pengelolaan limbah padat, d) penggunaan bahan kimia dalam proses produksi. Dalam hal ini ada empat faktor kunci yang sesuai yaitu meliputi (1) implementasi dan (2) alokasi dana terkait konservasi air, serta (3) teknologi dan (4) implementasi pengelolaan limbah B3/kimia.

Pada faktor kunci pengelolaan kawasan industri terdapat beberapa perbedaan apabila dibandingkan dengan faktor kunci pada pengembangan kawasan industri. Pada pengembangan kawasan industri, menurut Kodrat (2006) terdapat 5 faktor kunci sebagai faktor strategis masa depan, yaitu jumlah industri, permintaan lahan, kebijakan pemerintah, modal pengembangan dan iklim investasi yang kondusif. 


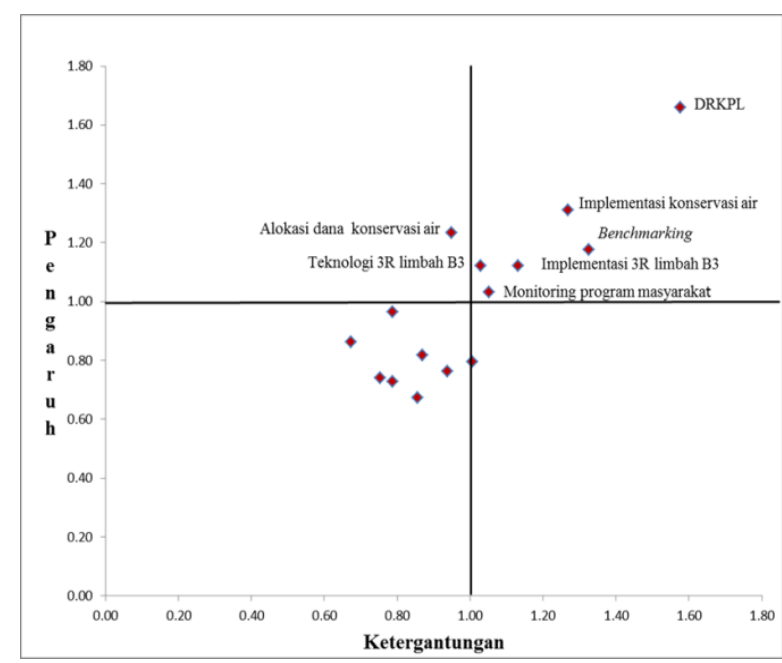

Gambar 12. Pemetaan faktor-faktor pengungkit pengelolaan lingkungan kawasan industri

Tabel 2. Faktor-faktor penting hasil analisis prospektif

\begin{tabular}{|c|c|c|c|c|}
\hline No & Dimensi & $\begin{array}{l}\text { Nilai indeks } \\
\text { keberlanjutan } \\
\quad 2014\end{array}$ & $\begin{array}{l}\text { Status keberlanjutan } 2014 \\
\text { sebagai base line }\end{array}$ & $\begin{array}{l}\text { Faktor penting hasil analisis } \\
\text { prospektif sebagai dasar perumusan } \\
\text { skenario kebijakan masa depan }\end{array}$ \\
\hline 1 & Ekologi & 40.87 & Kurang berkelanjutan & $\begin{array}{l}\text { Implementasi konservasi air dan } \\
\text { penurunan beban pencemaran air } \\
\text { limbah } \\
\text { Implementasi } 3 \mathrm{R} \text { limbah B3 }\end{array}$ \\
\hline 2 & Ekonomi & 35.06 & Kurang berkelanjutan & $\begin{array}{l}\text { Alokasi dana konservasi air dan } \\
\text { penurunan beban pencemaran air }\end{array}$ \\
\hline 3 & Sosial & 28.58 & Kurang berkelanjutan & $\begin{array}{l}\text { Monitoring dan evaluasi program } \\
\text { pengembangan masyarakat }\end{array}$ \\
\hline 4 & Teknologi & 16.53 & Tidak berkelanjutan & Teknologi 3R limbah B3 \\
\hline 5 & Kelembagaan & 66.91 & Cukup berkelanjutan & $\begin{array}{l}\text { DRKPL } \\
\text { Benchmarking }\end{array}$ \\
\hline
\end{tabular}

Kajian tetang pengembangan kawasan industri juga dilakukan oleh Guo dan Hu (2011), yang melakukan penelitian tentang kawasan industri di Lubei Tiongkok. Penelitian ini menyajikan wawasan empiris tentang teknologi "hijau" yang mempengaruhi evolusi menuju kawasan industri ramah lingkungan (eco industrial estate). Menurut Guo dan Hu (2011), hasil identifikasi faktor lingkungan yang pentingberpengarauh pada teknologi hijau adalah kebijakan lingkungan, dukungan finansial, ilmu pengetahuan, kondisi pasar, kebudayaan dalam berorganisasi, dan ketersediaan sumber daya.

Perbedaan-perbedaan faktor-faktor penting ini karena adanya perbedaan fokus pada tujuan kegiatannya. Pada pengelolaan kawasan industri lebih fokus pada mengelola jumlah industri yang ada, sedangkan pada pengembangan kawasan industri lebih fokus pada penambahan jumlah industri. Selain juga adanya perbedaan kondisi ekonomi, politik dan sosial di lokasi / negara kawasan industri tersebut berada. Namun demikian, dari berbagai kajian pengelolaan dan pengembangan kawasan industri tersebut terdapat kesamaan, yaitu mempunyai faktor kunci keberlanjutan yang sama yaitu terkait pada faktor lingkungan, ekonomi, sosial, teknologi dan kelembagaan.
Skenario pengelolaan lingkungan kawasan industri disusun berdasarkan faktor-faktor kunci yang berpengaruh pada pengelolaan lingkungan kawasan industri sesuai kriteria PROPER KLHK peringkat hijau. Dari faktor-faktor kunci tersebut dideskripsikan berbagai keadaan (state) yang mungkin akan terjadi di masa mendatang. Dari ketujuh faktor kunci (variabel) yang berpengaruh terhadap pengelolaan lingkungan kawasan industri, selanjutnya bersama manajemen KIJA dipilih keadaan yang mungkin terjadi di masa mendatang (Tabel 3).

Tabel 3. Kondisi (state) yang mungkin terjadi di waktu mendatang pada setiap faktor kunci

\begin{tabular}{|c|c|c|c|c|}
\hline \multirow[t]{2}{*}{ Faktor } & \multirow{2}{*}{$\begin{array}{c}\text { Kode } \\
\text { Variabel } \\
\text { (faktor kunci) }\end{array}$} & \multicolumn{3}{|c|}{$\begin{array}{l}\text { Kondisi (state) yang mungkin terjadi di waktu } \\
\text { mendatang }\end{array}$} \\
\hline & & A & B & $\mathrm{C}$ \\
\hline DRKPL & 1 & Meningkat & Tetap & Menurun \\
\hline $\begin{array}{l}\text { Implementasi konservasi air dan } \\
\text { penurunan beban pencemaran air limbah }\end{array}$ & 2 & Meningkat & Tetap & Menurun \\
\hline $\begin{array}{l}\text { Alokasi dana konservasi air dan } \\
\text { penurunan beban pencemaran air }\end{array}$ & 3 & Meningkat & Tetap & Menurun \\
\hline $\begin{array}{l}\text { Monitoring dan evaluasi program } \\
\text { pengembangan masyarakat }\end{array}$ & 4 & Meningkat & Tetap & Menurun \\
\hline Implementasi 3R limbah B3 & 5 & Meningkat & Tetap & Menurun \\
\hline Teknologi 3R limbah B3 & 6 & Meningkat & Tetap & Menurun \\
\hline Benchmarking & 7 & Meningkat & Tetap & Menurun \\
\hline
\end{tabular}

Pada Tabel 3 dapat dilihat bahwa setiap faktor kunci terdapat masing-masing tiga kemungkinan kinerjanya yang dapat terjadi di masa mendatang, yaitu tetap, meningkat atau menurun. Setiap faktor kunci diberikan kode nomor 1 sampai dengan nomor 7, sedangkan keadaan yang mungkin terjadi diberikan kode $\mathrm{A}$ (meningkat), B (tetap), dan C (menurun).

Selanjutnya dari berbagai kemungkinan sesuai Tabel 3 tersebut disusun kombinasi kondisi faktorfaktor kunci yang tidak mungkin terjadi secara bersamaan. Kombinasi antar kondisi faktor kunci (variabel) yang tidak mungkin tersebut selanjutnya di buang (dieliminasi) dalam penyusunan skenario lebih lanjut

Menurut Hardjomidjojo (2002), penyusunan skenario dimaksudkan untuk memprediksi kemungkinan yang dapat terjadi pada faktor tersebut, yaitu apakah akan berkembang ke arah yang lebih baik dari sekarang, tetap, atau akan semakin buruk dari keadaan sekarang. Skenario disusun dalam rangka menghasilkan rekomendasi operasional kebijakan pengelolaan lingkungan kawasan industri sesuai kriteria PROPER KLHK peringkat hijau untuk di masa depan. Pemetaan keadaan faktor penentu pengelolaan lingkungan kawasan industri sesuai kriteria PROPER KLHK peringkat hijau pada Tabel 4.

Berdasarkan hasil pemetaan pada Tabel 4, dan setelah deliminasi kombinasi keadaan yang tidak mungkin terjadi, disusun skenario kebijakan pengelolaan lingkungan kawasan industri. Kondisi sekarang sesuai data tahun 2014 (base line) merupakan kondisi awal untuk penentuan berbagai skenario. Pada Tabel 4 
dapat dilihat bahwa faktor-faktor kunci yang berpengaruh tersebut apabila dibandingkan dengan kontribusinya terhadap nilai PROPER sebesar 336.5 dari nilai maksimal 950, atau sebesar $35.4 \%$ sesuai Peraturan Menteri LH No 03 tahun 2014. Dengan melihat seberapa besar kontribusi faktor berpengaruh tersebut terhadap nilai PROPER dapat digunakan untuk menentukan prioritas terhadap skenario kebijakan yang paling implementatif dengan nilai yang besar.

Sebenarnya banyak kemungkinan skenario kebijakan yang dapat disusun, namun pada penelitian ini dibatasi hanya tiga skenario yang dikembangkan yaitu skenario pesimis, moderat dan optimis (Tabel 5).

Tabel 4. Pemetaan keadaan faktor-faktor penentu pengelolaan lingkungan kawasan industry sesuai kriteria PROPER KLHK hijau

\begin{tabular}{|c|c|c|c|c|}
\hline Faktor & $\begin{array}{l}\% \text { - terhadap } \\
\text { nilai proper }\end{array}$ & \multicolumn{3}{|c|}{ Keadaan (state) } \\
\hline DRKPL & $15.8 \%$ & \begin{tabular}{l}
\multicolumn{1}{c}{ 1A } \\
Semakin meningkat karena \\
adanya pelatihan-pelatihan \\
penyusunan DRKPL yang \\
informatif dan memenuhi \\
ketentuan sehingga \\
melampaui peningkatan \\
kemampuan perusahaan lain \\
(pesaing)
\end{tabular} & \begin{tabular}{l}
\multicolumn{1}{c}{$\mathbf{1 B}$} \\
Tetap seperti sekarang, \\
peningkatan kemampuan \\
penyusunan DRKPL \\
termasuk rata-rata terhadap \\
perusahaan lain (pesaing) \\
$\qquad$
\end{tabular} & \begin{tabular}{l}
\multicolumn{1}{c}{ 1C } \\
Peningkatan kemampuan \\
penyusunan DRKPL di \\
bawah rata-rata terhadap \\
kemampuan perusahaan lain \\
(pesaing) \\
(pes)
\end{tabular} \\
\hline $\begin{array}{l}\text { Implementasi konservasi } \\
\text { air dan penurunan beban } \\
\text { pencemaran air limbah }\end{array}$ & $4.4 \%$ & $\begin{array}{l}\text { Semalin meningkat dengan } \\
\text { perbaikan sistern distribusi air } \\
\text { bersih dan pene fakan } \\
\text { peratufan terhadap industri }\end{array}$ & $\begin{array}{l}\text { Tetap seperti sekarang, } \\
\text { implementasi konservasi air } \\
\text { tidak meningkat dạdn beban } \\
\text { pencemaran air linbah tidak } \\
\text { berkurang }\end{array}$ & $3 \mathrm{C}$ \\
\hline $\begin{array}{l}\text { Alokasi dana konservasi } \\
\text { air dan penurunan beban } \\
\text { pencemaran air }\end{array}$ & $1.6 \%$ & $\begin{array}{l}\text { Semak in meningkat dengan } \\
\text { adanyd alokasi dana rutin } \\
\text { tahunah untuk pjogram } \\
\text { konselvasi air dan penurunan } \\
\text { bebanlpencemazan air }\end{array}$ & $\begin{array}{l}\text { Tetap seperti sekarang, tidak } \\
\text { ada alokasi dana program } \\
\text { konservasi air dan,penurunan } \\
\text { beban pencemaran air }\end{array}$ & \\
\hline $\begin{array}{l}\text { Monitoring dan evaluasi } \\
\text { program pengembangan } \\
\text { masyarakat }\end{array}$ & $1.8 \%$ & $\begin{array}{l}\text { Semakin meningkat dengan } \\
\text { adanyd monitoring dan } \\
\text { evaluałi prograrh } \\
\text { pengephbangan masyarakat } \\
\text { serta npelibatkan|partisipasi } \\
\text { pihak perkait }\end{array}$ & $\begin{array}{l}\text { Tetap seperti sekarang, tidak } \\
\text { ada monitgring dan evaluasi } \\
\text { program płngembangan } \\
\text { masyaraka }\end{array}$ & $4 \mathrm{C}$ \\
\hline $\begin{array}{l}\text { Implementasi 3R limbah } \\
\text { B3 }\end{array}$ & $4.4 \%$ & $\begin{array}{l}\quad \text { SA } \\
\text { Semalyin meningkat dengan } \\
\text { optimąi IPAL yntuk } \\
\text { mengupangi limbah B3 dan } \\
\text { pening atan kerjasama } \\
\text { pemanfaatan limbah B3 } \\
\text { dengap pihak eksternal } \\
\quad 6 \text { A }\end{array}$ & $\begin{array}{l}\text { TB } \\
\text { Tetap seperti sekarang, tidak } \\
\text { terjadi pentngkatani } \\
\text { pengurangan dan } \\
\text { pemanfaatan limbahh B3 }\end{array}$ & $5 \mathrm{C}$ \\
\hline Teknologi 3R limbah B3 & $6.3 \%$ & $\begin{array}{l}\text { Semak in meningkat dengan } \\
\text { diseminasi teknologi 3R } \\
\text { limbahl B3 di jurnal ilmiah } \\
\text { minimall tingkat nasional } \\
\qquad \quad \text { 7A } \\
\text { Semakin meningkat karena } \\
\text { termasuk dalam minimal } 5 \\
\text { besar tingkat nasional di } \\
\text { bidang efisiensi air, efisiensi } \\
\text { energi, 3R limbah B3, 3R } \\
\text { limbah non B3, penurunan } \\
\text { emisi udara dan kehati }\end{array}$ & $\begin{array}{l}\text { Tetap seperti sekarangs tidak } \\
\text { dilakukan Anowledge } \\
\text { manlagem \&nt terkait } \\
\text { teknologi } 3 \mathrm{R} \text { limbah B3 } \\
\downarrow \\
\text { Tetap seperti sekarang, yang } \\
\text { mendapat penghargaan di } \\
\text { tingkat minimal tingkat } \\
\text { nasional hanya program } \\
\text { pengembangan masyarakat }\end{array}$ & $\begin{array}{l}\text { 7C } \\
\text { Semaki menurun dengan } \\
\text { tidak mendapatkannya } \\
\text { penghargaan sama sekali } \\
\text { pada semua bidang }\end{array}$ \\
\hline Total nilai faktor penting & $35.4 \%$ & 336.5 & & \\
\hline Total nilai proper & $100.0 \%$ & 950.0 & & \\
\hline Keterangan : & $\begin{array}{l}\overline{----} \\
-\cdot-- \\
-----\end{array}$ & $\begin{array}{l}\text { Kondisi base line saat ini }(20 \\
\text { Skenario pesimis } \\
\text { Skenario moderat } \\
\text { Skenario optimis }\end{array}$ & & \\
\hline
\end{tabular}

Tabel 5. Skenario pengelolaan lingkungan kawasan industri sesuai PROPER KLHK hijau

\begin{tabular}{ccc}
\hline $\begin{array}{c}\text { Kondisi sekarang } \\
\text { (base line })\end{array}$ & 1B - 2B - 3B - 4B - 5B - 6B - 7B \\
\hline No & Skenario & Keadaan \\
\hline 1 & Pesimis & $1 \mathrm{C}-2 \mathrm{~B}-3 \mathrm{~B}-4 \mathrm{~B}-5 \mathrm{~B}-6 \mathrm{~B}-7 \mathrm{C}$ \\
2 & Moderat & $1 \mathrm{~A}-2 \mathrm{~A}-3 \mathrm{~A}-4 \mathrm{~A}-5 \mathrm{~A}-6 \mathrm{~B}-7 \mathrm{~B}$ \\
3 & Optimis & $1 \mathrm{~A}-2 \mathrm{~A}-3 \mathrm{~A}-4 \mathrm{~A}-5 \mathrm{~A}-6 \mathrm{~A}-7 \mathrm{~A}$ \\
\hline
\end{tabular}

Skenario pesimis merupakan keadaan yang mungkin terjadi apabila ada penurunan kemampuan perusahaan bersaing dengan perusahaan lain sesama kandidat PROPER peringkat hijau dalam penyusunan DRKPL sehingga nilai DRKPL tidak termasuk melebihi ratarata dari seluruh kandidat PROPER hijau. Dalam keadaan ini sesuai prosedur yang berlaku menurut peraruran Menteri Lingkungan Hidup No 03 tahun 2014, pihak perusahaan langsung gagal dalam proses 
penilaian lebih lanjut. Dalam skenario pesimis juga terjadi penurunan dari diperolehnya penghargaan atas program pengembangan masyarakat yang selama ini hampir setiap tahun diperoleh.

Skenario moderat merupakan keadaan yang terjadi apabila perusahaan melakukan prioritas program dengan pertimbangan kebijakan yang: (a) faktor yang berpengaruh mutlak sebagai syarat kandidat PROPER hijau: DRKPL; (b) faktor-faktor dengan kontribusi nilai yang tinggi: DRKPL, implementasi 3R limbah B3 dan implementasi konservasi air; (c) faktor-faktor yang terjangkau dari segi alokasi dana dan dengan kemampuan sumber daya manusia yang tersedia: monitoring dan evaluasi program pengembangan masyarakat dan alokasi dana konservasi air. Pada skenario moderat ini, faktor benchmarking dan teknologi 3R limbah B3 tidak dilakukan peningkatan program karena selain memerlukan dana yang besar, juga keterbatasan sumber daya manusia dan daya dukung infrastruktur. Hal ini karena untuk meningkatkan nilai faktor teknologi 3R limbah B3, minimal ada diseminasi tentang inovasi teknologi ke dalam jurnal ilmiah bahkan mendapatkan hak paten dari pihak yang berwenang. Untuk benchmarking minimal harus masuk dalam lima besar tingkat nasional.

Skenario optimis merupakan keadaan yang terjadi apabila perusahaan melakukan upaya dan dukungan total untuk meningkatkan semua tujuh faktor penting yang mempengaruhi pengelolaan lingkungan kawasan industri sesuai kriteria PROPER KLHK peringkat hijau. Dalam skenario ini diperlukan alokasi dana yang sangat besar serta rekrutmen sumber daya manusia baru yang kompeten dan kemampuan ilmiah yang tinggi.

Skenario pesimis tidak direkomendasikan karena sesuai uraian di atas menghasilkan sistem yang tidak berkelanjutan, sedangkan skenario moderat dan optimis menghasilkan sistem yang berkelanjutan.

Berdasarkan perbedaan kontribusi nilai PROPER sebesar $7.3 \%$ (lihat Tabel 4), antara skenario moderat dan optimis dibandingkan dengan upaya yang sangat berat harus dilaksanakan perusahaan, maka skenario kebijakan moderat merupakan skenario yang lebih implementatif. Hal ini dengan pertimbangan skenario kebijakan moderat telah mendukung keberlanjutan sistem pengelolaan lingkungan kawasan industri sehingga memenuhi kriteria PROPER KLHK peringkat hijau dengan sasaran program yang lebih memungkinkan tercapai (achieveable) dari segi alokasi dana, ketersediaan sarana-prasarana, waktu, dan kemampuan sumber daya manusia

Skenario moderat juga direkomendasikan oleh Kodrat (2006) dalam pengembangan kawasan industri Medan. Menurut Kodrat (2006), skenario moderat pada pengembangan kawasan industri terpadu berwawasan lingkungan dapat dilakukan dengan kebijakan yang mencakup jumlah industri bertambah secara bertahap dengan meningkatnya permintaan lahan, serta kebijakan pemerintah yang memfasilitasi peningkatan modal pengembangan, dan didukung oleh iklim investasi yang kondusif.

\section{Kesimpulan}

1. Hasil analisis multidimensional scaling (MDS) dari data pengelolaan lingkungan kawasan industri berdasarkan data tahunan dari tahun 2008 sampai dengan tahun 2014 disimpulkan bahwa pengelolaan KIJA masih belum berkelanjutan sesuai kriteria PROPER KLHK peringkat hijau berdasarkan Peraturan Menteri Lingkungan Hidup No 03 tahun 2014 meskipun secara umum ada kecenderungan peningkatan nilai indeks keberlanjutan dari tahun 2008 sampai dengan 2014.

2. Dari hasil analisis multidimensional scaling (MDS) tahun 2014 sebagai baseline, disimpulkan bahwa status dimensi teknologi tidak berkelanjutan, dimensi ekologi, ekonomi, sosial kurang berkelanjutan, sedangkan dimensi kelembagaan cukup berkelanjutan. Keberlanjutan dimensi kelembagaan ini didukung dengan telah diperolehnya sertifikasi ISO 9001: 2008 untuk mutu, ISO 14001:2004 untuk sistem manajemen lingkungan, OHSAS 18001: 2007 untuk kesehatan dan keselamatan kerja.

3. Dari hasil analisis MDS kondisi tahun 2014 disimpukan terdapat 15 faktor-faktor pengungkit dalam pengelolaan kawasan industri yaitu :

a. Ekologi: (1) implementasi 3R Limbah B3, (2) implementasi penurunan pencemaran emisi udara, dan (3) implementasi penurunan konservasi air dan penurunan beban pencemaran air limbah.

b. Ekonomi: (4) alokasi dana untuk implementasi penurunan konservasi air dan penurunan beban pencemaran air limbah, (5) implementasi program penurunan pencemaran emisi udara, (6) implementasi program 3R limbah B3, (7) implementasi pengembangan masyarakat, dan (8) implementasi sistem manajemen lingkungan.

c. Sosial: (9) monitoring dan evaluasi program pengembangan masyarakat, serta (10) hubungan sosial internal dan eksternal.

d. Teknologi: (11) program penurunan pencemaran udara, (12) program 3R limbah B3, dan (13) audit dan efisiensi energi.

e. Kelembagaan: (14) benchmarking, dan (15) DRKPL.

4. Berdasarkan analisis prospektif pada faktor-faktor pengungkit dari hasil analisis MDS diperoleh kesimpulan terdapat tujuh faktor-faktor penting dan berpengaruh dalam pengelolaan lingkungan kawasan industri yaitu: (1) DRKPL, (2) implementasi program 3R limbah B3, (3) implementasi konservasi air dan penurunan beban pencemaran air, (4) alokasi dana konservasi air dan penurunan beban pencemaran air, (5) monitoring dan evaluasi program pengembangan masyarakat, (6) teknologi 3R limbah B3, dan (7) benchmarking.

5. Berdasarkan faktor-faktor penting dan berpengaruh hasil dari analisis prospektif disusun skenario kebijakan pesimis, moderat dan optimis pada keadaan yang mungkin terjadi di masa depan. Skenario kebijakan moderat direkomendasikan sebagai skenario yang paling implementatif. Hal ini dengan 
pertimbangan prioritas peningkatan pada faktorfaktor penting yang berkontribusi besar pada nilai PROPER, ketersediaan alokasi dana, kemungkinan pencapaian, ketersediaan infrastruktur, serta kemampuan sumber daya manusia. Faktor-penting berpengaruh dominan yang ditingkatkan dalam skenario moderat adalah (1) DRKPL, (2) implementasi program 3R limbah B3, (3) implementasi konservasi air dan penurunan beban pencemaran air, (4) alokasi dana konservasi air dan penurunan beban pencemaran air, (5) monitoring dan evaluasi program pengembangan masyarakat.

\section{Daftar Pustaka}

[1] Byl, R., Trainmar, Guadeloupe, 2002. Strategic Planning Using Scenario. IAME, Panama City.

[2] Dewi, H., 2009. Analisis pengaruh investasi dan tenaga kerja terhadap output sektor industri di Kabupaten Bekasi. Skripsi. Institut Pertanian Bogor, Bogor.

[3] Fauzy, A., S. Anna, 2005. Permodelan Sumberdaya Perikanan dan Kelautan untuk Analisis Kebijakan. PT Gramedia Pustaka Utama, Jakarta.

[4] Ghasemian, M., P. Poursafa, M. M. Amin, M. Ziarati, H. Ghoddousi, S. A. Momeni, A. H. Rezaei, 2012. Research article: environmental impact assessment of industrial estate development plan with GIS and matrix methods. Journal of Environmental and Public Health. Article ID 407162, 8 pages doi: $10.1155 / 2012 / 407162$.

[5] Guo, L. X. Hu, 2011. Green technological trajectories in eco-industrial parks and the selected environment. The cases study of the Lubei Group and the Guitang Group. Journal of knowledgebased Innovation in China 3(1), pp. 54-68.

[6] Hartrisari, 2007. Sistem Dinamik: Konsep Sistem dan Pemodelan untuk Industri dan Lingkungan. SEAMEO BIOTROP, Bogor.

[7] Jampanil, J., K. Dabbhadatta, P. Petcharuttana, B. Kawinvasin, P. Tananon, K. Poommai, 2012. Environmental Sustainability by Eco-Industrial Network approach Project: Maptaphut Industrial Estate Complex in Thailand, NPC Safety and Environment Service. Industrial Estate Authority of Thailand.

[8] Kavanagh, P., T. J. Pitcher, 2004. Implementing Microsoft Excel software for Rapfish: a technique for the rapid appraisal of fisheries status. Fisheries Centre Research Reports 12(2). University of British Columbia, Vancouver.

[9] Kodrat, K. F., 2006. Analisis sistem pengembangan kawasan indutri terpadu berwawasan lingkungan (studi kasus pada PT Kawasan Industri Medan). Disertasi. Sekolah Pasca Sarjana, Institut Pertanian Bogor, Bogor.

[10] $[\mathrm{KLH}]$ Kementerian Lingkungan Hidup, 2012. The Gold for Green. Kementerian Lingkungan Hidup, Jakarta.

[11] Napitupulu, A., 2009. Pengembagan model kebijakan pengelolaan lingkungan berkelanjutan pada PT (Persero) Kawasan Berikat Nusantara. Disertasi. Sekolah Pasca Sarjana, Institut Pertanian Bogor, Bogor.

[12] Salim, J., A. Saefuddin, Marimin, E. Riani, 2009. Strategi pengelolaan limbah baja di wilayah pesisir kawasan industri Krakatau Cilegon. Jurnal Pengelolaan dan Sumber Daya Alam dan Lingkungan 4(1), Institut Pertanian Bogor, Bogor.

[13] Salmi, O., A. Toppinen, 2007. Embedding science in politics: "complex utilization" and industrial ecology as models of natural resource use. Journal of Industrial Ecology 11(3), pp. 93-111.

[14] Suyitman, 2010. Model pengembangan kawasan agropolitan berkelanjutan berbasiskan peternkan sapi potong terpadu di Kabupaten Situbondo. Disertasi. Sekolah Pasca Sarjana, Institut Pertanian Bogor, Bogor. 